Fetal Diagnosis and Therapy
Fetal Diagn Ther 2012;32:5-16

DOI: $\underline{10.1159 / 000335649}$
Received: November 15, 2011

Accepted after revision: December 2, 2011 Published online: May 15, 2012

\title{
Myocardial Motion and Deformation: What Does It Tell Us and How Does It Relate to Function?
}

\author{
B. Bijnens ${ }^{a, b} \quad$ M. Cikes ${ }^{f} \quad$ C. Butakoff ${ }^{b} \quad$ M. Sitges ${ }^{c} \quad$ F. Crispid ${ }^{d, e}$
}

anstitució Catalana de Recerca i Estudis Avançats (ICREA), buniversitat Pompeu Fabra, ' Cardiology Department, Thorax Clinic Institute, and d Department of Maternal-Fetal Medicine, Institut Clínic de Ginecologia, Obstetrícia i Neonatologia, Hospital Clinic, Institut d'Investigacions Biomèdiques August Pi i Sunyer, University of Barcelona,

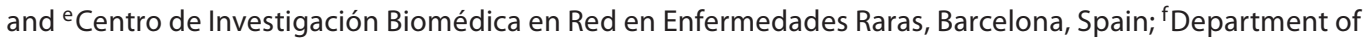
Cardiovascular Diseases, University Hospital Centre Zagreb, University of Zagreb School of Medicine,

Zagreb, Croatia

\section{Key Words}

Cardiac function - Myocardial deformation - Strain (-rate) •

Pressure-volume overload $\cdot$ Fetal cardiac mechanics dial mechanics and physiology, opens new perspectives to improve the assessment and management of fetal, pediatric, and adult patients.

\begin{abstract}
The assessment of cardiac pump function and the potential of local myocardium to contribute to the overall performance are of great importance in many cardiovascular abnormalities. Assessing intrinsic cardiac function requires obtaining information on the true contractility of the heart muscle, assessed locally but interpreted in the context of its contribution to the global ejection performance and potential to adapt to changing circumstances. Contemporary imaging techniques offer the possibility of noninvasive quantification of myocardial deformation. These new clinical tools are attractive to use for the assessment of ventricular function. However, it is of great importance to understand cardiac mechanics - a complex interplay between the tissue structure/shape, force development, and interaction with the environment/neighbors - to interpret alterations in deformation and to extract clinically relevant conclusions. The combination of insight into the measurement techniques and their limitations, together with knowledge of myocar-
\end{abstract}

\section{KARGER}

Fax +4161306 1234

E-Mail karger@karger.ch

www.karger.com
(C) 2012 S. Karger AG, Basel

$1015-3837 / 12 / 0322-0005 \$ 38.00 / 0$

Accessible online at:

www.karger.com/fdt

\section{Introduction}

The assessment of cardiac pump function and the potential of local myocardium to contribute to the overall performance are of great importance in many cardiovascular abnormalities in the fetus, the child, and the adult. However, the quantification of intrinsic (dys-)function is not straightforward due to the ambiguity of the definition of function and the need for quantitative parameters that provide guidance in clinical diagnosis and treatment. Assessing intrinsic cardiac function requires obtaining information on the true contractility of the heart muscle, assessed locally but interpreted in the context of its contribution to the global ejection performance and potential to adapt to changing circumstances. Current clinical tools, mainly based on (preferably noninvasive) cardiovascular imaging, provide helpful information despite not being able to assess true contractile function. 
Fig. 1. Determining components of 'cardiac function'.

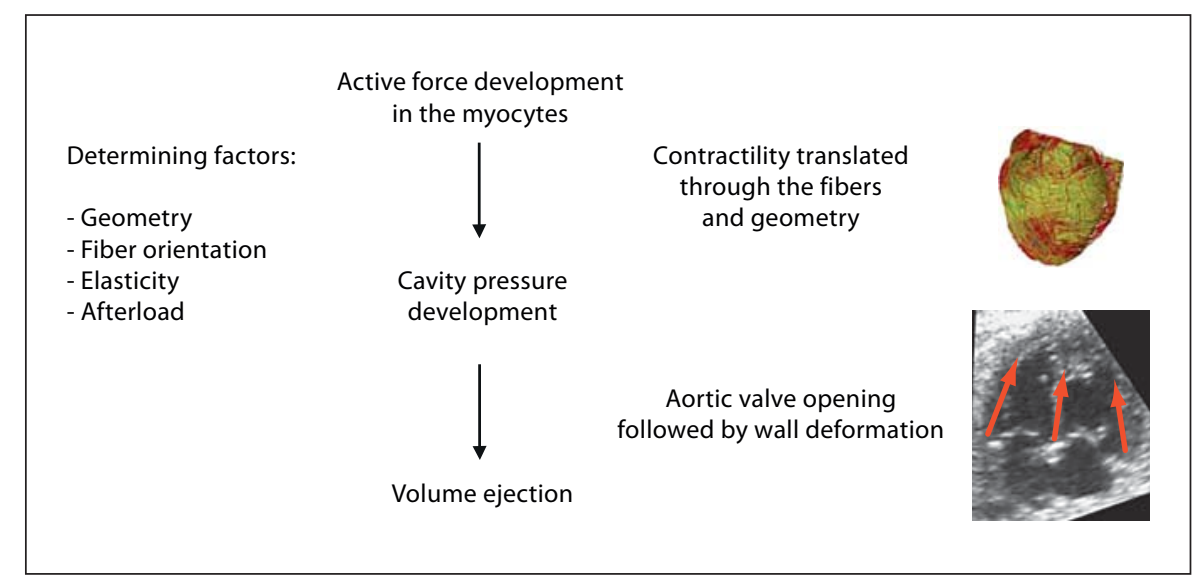

Understanding how these measurements (e.g. volume changes and muscle deformation) are related to cardiac function and what their limitations are is crucial for their appropriate use in research and clinical practice.

\section{Factors Determining Cardiac Function}

Figure 1 shows a simplified overview of cardiac function and its determining factors [only focused on the left ventricle (LV) for clarity].

The main purpose of a ventricle is to provide the amount of stroke volume needed to generate the cardiac output required by the body to function and to be able to flexibly adapt to a changing demand (e.g. exercise) and changing working conditions (cardiovascular diseases). The primary building block of myocardium, the myocyte, can, when electrically activated, develop force and shorten. It is important to keep in mind, however, that a myocyte can maximally shorten by $10-15 \%$ [1]. The myocytes are arranged in muscle fibers that are organized in a very specific way within the LV wall. All of the muscle fibers form the LV walls encircle its cavity, and provide an overall shape (local geometry with a specific curvature and thickness). Besides its geometrical configuration, muscle tissue also has a specific (passive) elasticity that determines how it will deform under external forces.

When the myocytes are activated they start to develop force (in their longitudinal direction) and the accumulated force of all of the differently oriented cells is translated into an increase in cavity pressure, which, with all valves closed, might change the overall internal geometry. When the LV pressure is large enough to open the aortic valve, the myocytes can start to shorten, resulting in overall deformation of the tissue and leading to a reduction of the internal cavity size, thus effectively ejecting a certain volume of blood into the circulation.

Obviously, all of the factors influencing both pressure (force) generation and volume ejection (deformation) play a role in the global performance of the LV (fig. 1). Therefore, assessment of both the developed force and the resulting deformation is needed to describe cardiac function. Since the ventricles are not homogeneous (in terms of local shape, morphology, activation system, perfusion, or tissue composition), segmental assessment of force and deformation is required in most circumstances.

Understanding and assessing the relation between force and deformation requires knowledge of the boundary conditions, including local wall properties, fiber structure, segment interaction, coupling to the circulation, etc. Therefore, no single parameter can be used to understand an individual heart; rather, only an integrated assessment of force, deformation, local and global geometry, and interaction with the environment will provide the relevant information in most situations.

\section{Clinical Assessment of Cardiac Function}

In current clinical practice, we have no possibility to (noninvasively) quantify all of the information (on both pressures/forces and volumes/deformation), so decision making is based on an overall assessment by the clinician of all of the elements available. The (quantitative) data available come from clinical imaging (mainly echocardiography, since magnetic resonance imaging or computed tomography have limited applicability in fetal assessment). For follow-up, echocardiography is mostly the 
modality of choice and both 2D and blood-pool Doppler information is used to quantify volumes, size and thickness, and hemodynamic information such as pressure gradients between compartments and flow abnormalities.

\section{Global Ventricular Deformation: Volumes and Volume Changes}

Since the measurements of spatial dimensions and blood velocities through the valves are the most available quantification, current evaluation of cardiac function is mainly based on the assessment of volume-based parameters (from echocardiography).

End-diastolic (ED) and end-systolic (ES) volumes can be measured from M-mode (using the Teichholz formula, which is very inaccurate in the presence of ventricular shape changes) or from 2D images using the Simpson approach (much more accurate in ventricles with an abnormal shape) or from 3D images (best for abnormal shapes, but often with less spatial resolution and more artefacts). From these volumes, the fractional area change [(ED area - ES area)/ED area], the ejection fraction [(ED volume - ES volume)/ED volume], and the stroke volume (ED volume - ES volume) can be calculated. Stroke volume can also be assessed from the blood-pool Doppler (valve area multiplied by the velocity time integral from the Doppler velocities). The stroke volume multiplied by the heart rate provides the cardiac output.

The volume changes represent global ventricular ejection and thus the result of the overall deformation of the ventricle. Therefore, no information is available on how the ventricle manages to produce the volume difference. All segmental variability is averaged out in the volume measurements, and different components of deformation cannot be assessed individually.

Additionally, using this approach, no information about force development [this would require (invasive) pressure assessment] is available. Therefore, volumebased parameters are highly load dependent and changes in pressure and overall volume displacement will influence them independently of intrinsic contractility. Thus, assessment of loading conditions, especially during longitudinal follow-up or with therapy, is required to interpret the results.

\section{Regional Myocardial Deformation}

For understanding changes in cardiac mechanics with pathologies, knowledge of muscle architecture and its influence on different components of deformation is essential. Due to the given 3D fiber distribution within the wall, there are both longitudinal (from base to apex) and circumferential (within the short axis of the muscle) components of deformation, and different disease processes can independently affect these different components. Therefore, all potential geometrical changes during the cardiac cycle have to be assessed in order to evaluate ventricular function. Especially the decrease in longitudinal function, compensated for by increased circumferential contraction, might be totally masked by only assessing volume changes [2]. Additionally, segment interaction, especially in the isovolumic contraction [3] or relaxation [4] period, can result in important deformation of segments that does not contribute to ejection and thus induces no volume changes.

Recently, novel developments in the acquisition and processing of cardiac images (mainly in echocardiography and MRI) offer the possibility to quantify regional deformation of myocardial tissue. While, in the past, segmental deformation could only be assessed in the experimental setting using invasive techniques like sonomicrometry, these image-based deformation assessment tools offer the possibility to quantify deformation in more physiological conditions as well as to investigate patients in a clinical setting. In the past decade, this approach has contributed to a much better understanding of cardiac pathophysiology and the changes in deformation induced by a broad range of cardiac abnormalities [5-14].

\section{Quantifying Regional Motion and Deformation}

Current, noninvasive, ultrasound-based techniques to quantify motion and deformation are based on measurement of the temporal changes in the position or velocity of tissue points within the myocardium. In tissue Doppler imaging (TDI)-based techniques, the velocity (towards the transducer) of all points within the myocardium is recorded at a high temporal resolution, while in speckle tracking-based techniques points of the myocardium are identified and their position is followed from frame to frame. From the velocity or position change of points in the myocardium, several parameters can be quantified as follows.

\section{One Point-Based Measurements}

- Velocity: the velocity of a point (either measured directly by TDI or calculated from how the speckles change position) quantifies the speed at which this point is moving with regard to the transducer. If the transducer if fixed to the thorax (pediatric/adult), it refers to the speed of the point within the thorax, thus relating to how the myocardium contracts as well as to 
how it moves within the thorax. If the transducer is on the maternal abdomen, additionally the overall fetal motion within the uterus can influence the measured velocity.

- Motion (displacement): the motion or displacement of a point is the distance a point covers over a certain period of time. When using TDI, the motion towards the transducer is quantified while speckle tracking allows measurement of the motion within the scan plane.

\section{Two Point (Segment)-Based Measurements}

- Speed of deformation (strain rate): quantifies how fast 2 different points of the myocardium change position with regard to each other, and thus how fast they move towards or away from each other at a given moment. It therefore describes how fast the size of a segment is changing.

- Deformation (strain): deformation quantifies how 2 different points of the myocardium change position with regard to each other over a certain period of time and therefore describes how much the size of a segment of the myocardium is changing.

When applying these measurements to a ventricle, one can extract several quantitative parameters that have been used to describe regional function.

The accumulation of the longitudinal shortening of all segments results in the base being dragged closer towards the apex. Since the apex is stationary within the thorax, the atrioventricular valve plane will move towards the apex. The amount of motion of the valve rings towards the apex is referred to as their displacement. For example, in an apical 4-chamber view, one can measure the amount of displacement of the mitral ring, on the septal and lateral sides, and of the tricuspid ring at the free wall of the right ventricle. This last measurement is often referred to as TAPSE (tricuspid annular plane systolic excursion). The displacement of the base of a wall, measured at the level of the ring, provides an idea of the total change in length of that wall (assuming the apex is stationary) and thus corresponds to the overall shortening (deformation) of the wall. Ring displacement is a sensitive indicator of abnormal function in the wall since any change in any segment will be reflected in the amount and the timing of displacement [15-18].

Besides the deformation itself (which describes the change in length/thickness of a segment compared to its initial size - strain - expressed in \%), when assessing myocardial deformation, the speed at which this deformation is taking place (strain rate - expressed in $\mathrm{s}^{-1}$ ) is also relevant when investigating cardiac function.
While more and more literature on alterations of deformation [assessed noninvasively using Doppler-based strain (rate) assessment or speckle tracking on greyscale images] is becoming available, the physiological and clinical interpretation of these changes is not always straightforward, given that deformation does depend on the force developed by the myocardium, but at the same time is determined by the working conditions (loading), tissue properties, and interaction of different segments.

\section{Components of Myocardial Deformation}

The deformation of a myocardial segment during ejection is very complex [19]. Figure 2a illustrates the main components of myocardial motion and deformation. When the muscle fibers contract, all segments deform. While description of the detailed 3D deformation is challenging, the clinically relevant deformation components are longitudinal (in the base-to-apex direction), circumferential (along the short-axis circumference), and radial (from endo- to epicardium) (fig. 2).

To understand the detailed 3D deformation of a segment, its detailed morphology has to be taken into account, and the muscle fibers within the segment are the main determinants. In a mature heart, these fibers are arranged in a complex 3D geometry in order to enable a volume ejection of around $60 \%$ with building blocks that can only shorten by $10-15 \%$. This efficient ejection is achieved by a change in the direction of the fibers across the myocardial wall. Figure $2 \mathrm{~b}$ shows the fiber orientation in a porcine heart, extracted from diffusion tensor images [20]. At the epicardial surface of the LV, the fibers run in a longitudinal direction, from apex to base. When going from epi- to endocardium, the fibers gradually change angle so that the mid-myocardial fibers become circumferentially oriented (running around the ventricle in a short-axis plane) and the endocardial ones are longitudinal again. Endo- and epicardial fibers, although dominantly longitudinally oriented, run slightly oblique from base to apex.

When individual fibers contract, they deform along their fiber direction. Therefore, contraction of longitudinally oriented fibers results in deformation in the apexbase direction, moving the valve plane closer to the apex (in normal hearts, the apex remains relatively stationary within the thorax) and shortening the long-axis dimension of the heart. When circumferential fibers contract they shorten the circumference, thus decreasing the short-axis diameter and bringing opposite walls closer 
Fig. 2. Myocardial motion and deformation components (a) and fiber structure of the heart (b).
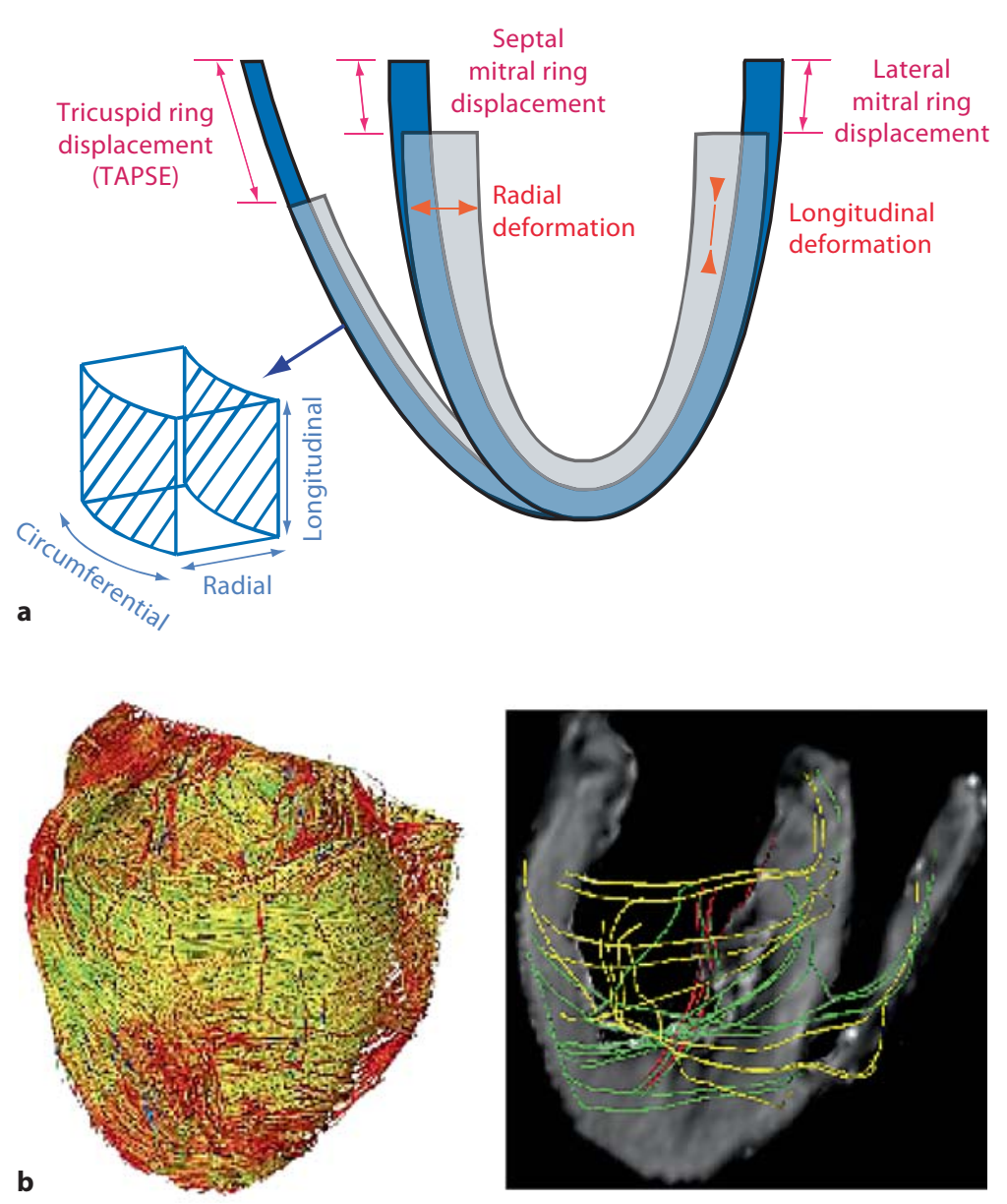

together. Since myocardial tissue is quasi uncompressible (except by the blood within the muscle being pressed out during systole), longitudinal and circumferential shortening (the 'active' deformation components) result in thickening in the radial direction (the 'passive' deformation component). Due to the slightly oblique orientation of the epi- and endocardial fibers, when contracting, they result in rotation of the basal plane with regard to the apical plane. The differential rotation of the apical and basal planes, normalized by the length of the ventricle, results in the overall torsion of the LV (expressed in degrees $/ \mathrm{m}$ ) $[21,22]$.

During fetal development, myocardial tissue forms in several stages [23]. Around 12 weeks, the ventricles reach their final shape and the muscle, which until then mainly consisted of a network of trabeculations, starts to compact and form its final fiber structure. The compaction of the wall continues until early neonatal life. Additionally, it has been shown that fetal conditions (especially pressure and volume load) can alter this compaction process, resulting in different distributions of fibers across the wall [24]. Little information is currently known about how the different stages of compaction influence the different deformational components or whether alterations during development have consequences for deformation/ function of pediatric and adult hearts.

The cumulative magnitude of all of these components results in the overall 3D deformation of the segment, thus contributing to the change in internal cavity size and volume ejection. However, while suggestions have been made to calculate the contribution of individual segments to the overall ejection $[25,26]$, this is extremely difficult, especially in pathological conditions, due to the integration of the segment into the whole muscle (constantly changing in overall position/shape) and the interaction of the neighboring segments. 
Fig. 3. Relation of ventricular size, stroke volume, and deformation.

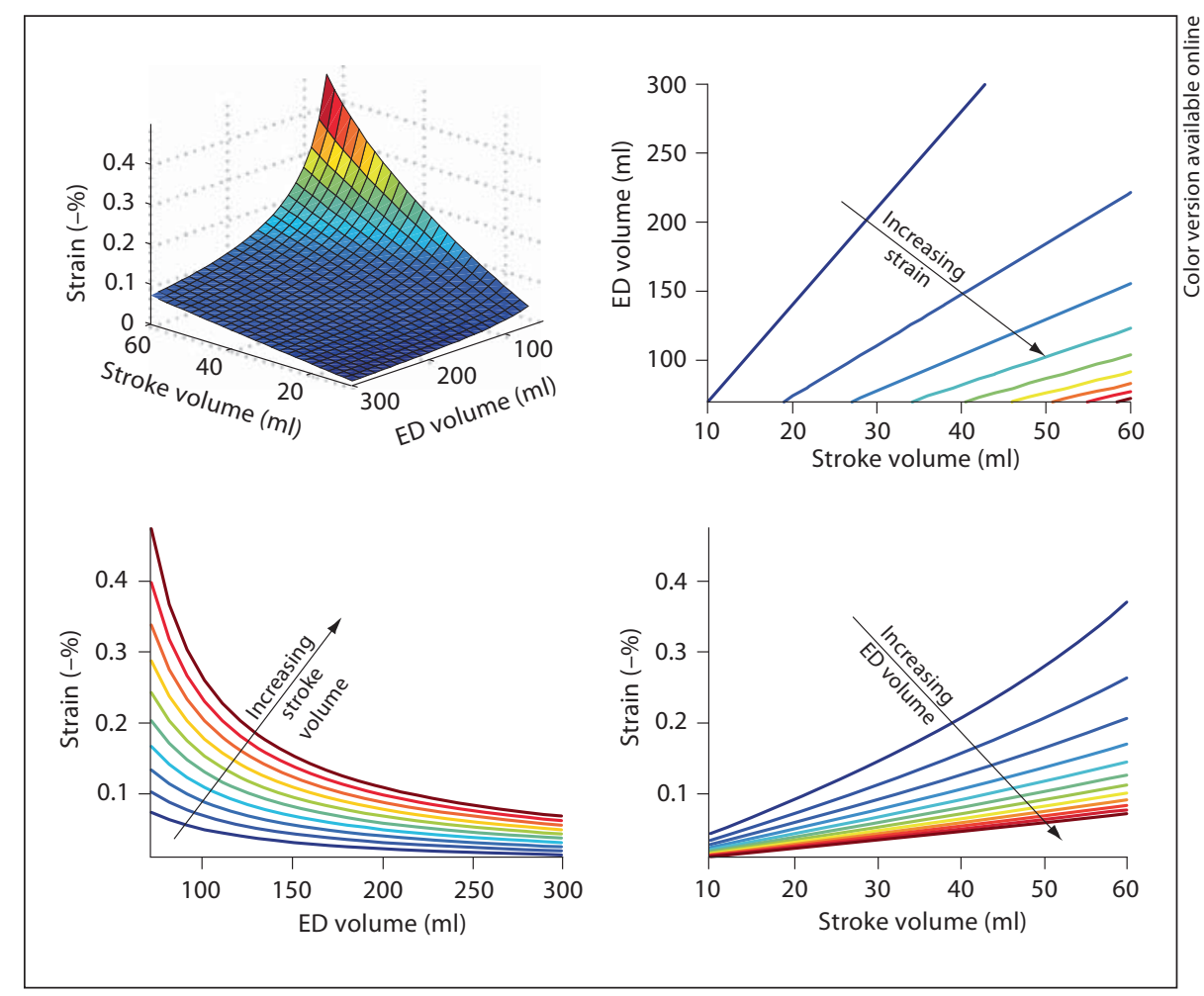

\section{Myocardial Deformation versus Ventricular Size}

As discussed above, the ventricle ejects a certain amount of blood with each heartbeat (stroke volume) by overall deformation of the cavity. This overall deformation is realized by the cumulative effect of the deformation of all of the individual segments. More segmental deformation for a given ventricle (e.g. with increased contractility or inotropic stimulation) will result in more overall deformation and therefore increased stroke volume (fig. 3) [27]. However, the overall size of the ventricle importantly determines the amount of stroke volume that can be generated with each contraction. With the same amount of segmental deformation, a larger ventricle can eject much more compared to a smaller one because the ejected volume is contained in the outer part of the cavity, which is obviously larger in a larger ventricle (fig. 3). To illustrate the importance of this effect: the $2-\mathrm{cm}$ outer shell of a sphere with a radius of $10 \mathrm{~cm}$ contains about the same volume as a whole sphere of $8 \mathrm{~cm}$ in radius.

This also implies that a bigger ventricle could generate the same amount of stroke volume as a smaller one with less segmental deformation [28]. During development and childhood, ventricular size as well as the required stroke volume is changing. This implies that deformation can be different when comparing different stages of fetal life or different age groups, although contractility is exactly the same [29]. Similarly, the difference in ventricular size between the sexes implies different normal deformation values [30].

This relationship is also used by the ventricle in order to remodel to adapt to changing conditions. If more stroke volume is required (e.g. with valve regurgitations or shunts), dilatation will provide a way to increase stroke volume with the same amount of segmental deformation. In the case of decreased contractility (e.g. with ischemia or genetic alterations), dilatation provides a way to generate the same amount of stroke volume with less deformation.

Similarly, during fetal development, a redistribution of volumes passing through each of the cardiovascular compartments is to be expected [31]. This gestational age-dependent volume change will influence the deformation of the different segments of the ventricles. 
Fig. 4. Relationship between local forces and deformation.

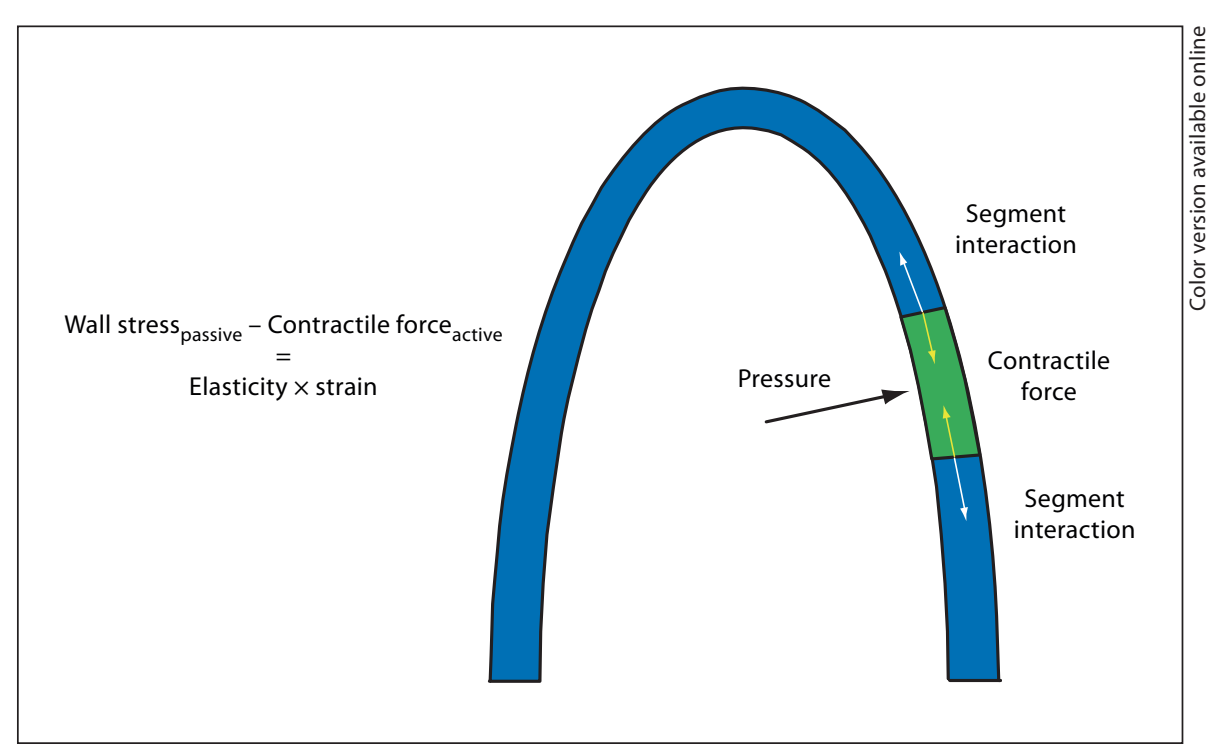

Therefore, when comparing different populations with different ventricular size or stroke volume, or when studying individuals during follow-up, when size or output is changing, care has to be taken to investigate the relation between size, deformation, stroke volume, and, in the fetus, gestational age.

\section{Myocardial Deformation versus Function}

It has been shown in numerous studies that deformation, or specifically some of its components, is changing in cardiovascular diseases. However, as stated above, deformation does not directly represent myocardial 'function' but is influenced by loading conditions and its local and global neighborhood. Therefore, it is important to understand local tissue mechanics, linking deformation to contractile force development by the tissue.

When assessing the deformation of an elastic object, Hooke's law of physics states that the amount of deformation is proportional to the force per unit area divided by the elastic modulus of the material (fig. 4). Therefore, a more elastic object will deform more when a similar force is applied to it. Since this is a universal law, it also holds true for myocardium. However, it is important to keep in mind that deformation in a certain direction is a result of the sum of all forces acting upon the object in that direction. Thus, to understand myocardial segmental deformation, one has to study all of the forces acting within and upon the segment. Among these forces, the contrac- tile force of the myocytes within the segment is the most evident. However, this is not the only force involved. Another important one is the 'pressure loading' resulting from the intracavitary pressure, acting perpendicular to the endocardial surface and translated into a circumferential and longitudinal wall stress component (depending on the local curvature) [32]. Besides these two 'obvious' forces, one should not forget that neighboring segments are closely connected to the segment under investigation and, when these contract, they exert a 'pulling force' on the segment. In normal myocardium, when all segments contract with similar forces this interaction is cancelled out, but when one segment, for example, can develop less force, there is a local imbalance of forces and the resulting force will play a potentially important role in the local deformation of the segment. Lastly, myocardial tissue (due to its matrix skeleton) becomes stiffer the more it is stretched, so there is the passive elastic force of the tissue (which can vary with disease processes) to take into account.

All of these forces are time variant, with sometimes very different timings (e.g. the active contractile force development goes down much earlier, during the ejection phase, compared to the intracavitary pressure), and the magnitude and direction of the forces is dependent on the overall and local shape of the ventricle.

Therefore, to interpret and understand changes in (regional) deformation, the combination of all of the above mentioned forces, and the relation with tissue elasticity, has to be investigated. 


\section{Changes with Cardiac Abnormalities}

From the information above, it is clear that myocardial deformation changes whenever one of its determining factors is altered. Easy access to noninvasive, imagebased technologies to assess regional deformation thus enables quantification of these changes and allows detection and follow-up of alterations and use of these for diagnosis, therapy guidance, and follow-up. During the past decade, a multitude of studies have improved our pathophysiological understanding and clinical knowledge of myocardial diseases and their associated changes in deformation. This knowledge, together with thorough insight into the (dis-)advantages of each of the quantitative techniques, provides a powerful tool to better understand an individual heart, both in a research and in the clinical setting.

To provide some examples of how deformation could be interpreted, the next sections will discuss cardiac mechanics and remodelling in some of the most frequently found abnormalities in fetal and adult hearts.

\section{Abnormal Contractility}

\section{Myocardial Hypoxia/Ischemia}

Many myocardial abnormalities are associated with changes in the contractile force development of some segments of a ventricle. While fetal abnormalities often change the volume and pressure loading of the heart, they might also result in hypoperfusion, decreasing the contractility and thus changing the deformation.

Myocardial hypoxia/ischemia can be induced in fetal life due to placental insufficiency, severe anemia, or other conditions $[33,34]$ and (rarely) due to coronary anomalies (such as abnormal origin of the coronary arteries) [35].

From the above description of the relation between deformation and function, it is clear that if the contractile force decreases (and it decreases linearly with the decrease in local perfusion [36]), the local deformation will decrease. Similarly, if contractility is increased (e.g. by administration of dobutamine), deformation (and especially the speed of deformation, i.e. strain rate) will increase (as long as the heart rate does not prevent complete filling). If hypo perfusion persists chronically, additionally the tissue elasticity will change due to fibrosis and necrosis and deformation will decrease even more. Since fetal conditions result in global ventricular changes, the overall deformation might be decreased and especially the rate of deformation might be smaller. In these cases, regional changes will be mainly determined by the induced overall remodelling and shape change and the alterations in (pressure) loading.

Deformation has been extensively studied in regionally reduced contractile force development due to coronary artery anomalies or narrowing (mainly in adults - coronary artery disease) [36]. Besides changes in the segmental contractile force, the segment interaction, with neighboring segments with retained perfusion, will become prominent [37]. When adjacent segments develop a different amount of force during systole, their deformation at end-systole is different. When the aortic valve subsequently closes and the pressure drops, this differential deformation results in exaggerated interaction of the segments and the segment with the lesser contractile force starts to show postsystolic shortening/thickening, which obviously does not contribute to ejection. Combination of systolic deformation together with postsystolic deformation provides a great deal of information about the contractility and tissue properties of the segments.

Besides hypoperfusion, the presence of edema is important in determining local tissue properties. In the presence of intracellular edema, e.g. in stunned myocardium [38] and potentially induced by some medications (such as chemotherapy agents), the contractile apparatus of the cell becomes less efficient and contractile force development decreases, resulting in less systolic deformation and the induction of postsystolic events. When gross, interstitial edema is present, such as that induced by reperfusion of a prolonged total coronary occlusion $[39,40]$, the tissue becomes very stiff and thickened, preventing any deformation, systolic or postsystolic.

\section{Genetic Cardiomyopathies}

In fetal life, genetic cardiomyopathies are an additional source of abnormal contractile functions [41]. The potential for the tissue to develop force and deform can be changed as a result of an abnormal genotype. Depending on the genetic defect, the properties of the myocytes (contractile apparatus, mitochondria, etc.) can change or the structure and distribution of the fibers and the supporting (collagen) matrix can be altered. Additionally, this can result in a segmentally different phenotype (such as local fiber disarray, which can be present in any segment, although predominantly in the septum, in hypertrophic cardiomyopathy) or in global tissue changes which, depending on the type, can become evident as deformation alterations in specific myocardial segments [42]. In typi- 
cal genetic cardiomyopathies, such as Fabry's disease [43], Friedreich's ataxia, or Duchenne muscular dystrophy, the basal inferolateral segment shows the first changes (decreased systolic + postsystolic) in deformation. Hypertrophic cardiomyopathy manifests as the presence of at least one segment, wherever it is localized, with almost total absence of deformation. The associated deposition within the myocardium in amyloidosis (acquired or hereditary) results in the inhibition of deformation of the endo- and epicardial fibers, thus markedly reducing longitudinal shortening, while circumferential/radial deformation is partially retained.

\section{Volume Overload}

When the amount of cardiac output to be generated increases importantly (e.g. anemia [33], tumors [44], intrauterine growth restriction [34], abnormal ductus venosus/shunts [45], twin-twin transfusion syndrome [46], valve leakage, etc.), the ventricle remodels to cope with this. As discussed above, when addressing the relation between size, deformation, and stroke volume, the natural response is to enlarge the cavity by ventricular dilatation. Additionally, the contractility can be slightly increased by increasing the amount of contractile material in the cells, thus increasing the myocardial mass (hypertrophy) so that more deformation can be induced. Therefore, the natural consequence of a slow chronic increase in volume load is an increase in ventricular dimensions (cardiomegaly) with a maintained, or slightly increased, strain [28]. However, the major disadvantage of increasing the ventricular size is that this changes the geometry and alters the local curvature and results in an increase in local wall stress with unaltered intracavitary pressure (since the translation of the pressure into the muscle is governed by the local shape). When wall stress becomes too high and cannot be overcome by increased contractility from hypertrophying, myocytes start to get damaged and matrix proteins are altered, resulting in local fibrosis and cell death. This both increase local stiffness and decreases contractility, thus inhibiting deformation. This decrease in deformation has to be compensated for to ensure enough stroke volume. This starts the fast, detrimental cycle of increasing dilation, further increasing wall stress and tissue damage, and ultimately leads to failure of the ventricle (inducing hydrops in fetal life), which can only be prevented by decreasing the volume load to a level where wall stress is tolerable for the tissue.

Myocardial Motion and Deformation

\section{Pressure Overload}

When for some reason (twin-twin transfusion syndrome - recipient [47], aortic or pulmonary stenosis [4850], external vascular compression due to fetal masses such as lower urinary tract obstruction [51], intrauterine growth restriction [14], etc.) the pressure that needs to be developed to get the blood flowing is increased, the wall stress in the tissue increases and thus triggers a remodelling response aimed at normalizing stress. The natural response is that the myocytes increase their potential for force development by increasing the amount of contractile material, thus inducing enlargement of the cells. This enlargement manifests as hypertrophy, preferentially also decreasing the cavity size, thus changing the local curvature towards a decrease in wall stress. Associated with this, and with reduced wall stress, is a change in the overall shape of the ventricles, from ellipsoid (with a much larger base-apex dimension compared to the transversal) towards a more spherical shape [14].

When not totally compensated for by increased force development, the increased pressure will decrease the rate of deformation, and deformation itself, if the force development cannot be maintained long enough. Therefore, another mechanism (besides hypertrophy) to cope with pressure loading is to develop force for a longer period during systole. This can actually be observed from, for example, the velocity profile of the aortic outflow, which in normal circumstances has a triangular shape, peaking early in systole, and becomes much more rounded, with a later peak, in cases of noncompensated pressure overload [52].

Since the curvature of the ventricle is markedly different in the longitudinal compared to the radial direction, the stress (change) observed by the longitudinal fibers is importantly higher. Therefore, when the cavity pressure increases, longitudinal deformation is altered much more compared to radial deformation (which might increase to compensate and to retain stroke volume). Measuring longitudinal function and comparing it to circumferential/ radial function is therefore absolutely required to understand the changes induced by pressure loading. Additionally, since the (longitudinal) endocardial fibers are more vulnerable compared to the (differently oblique longitudinal) epicardial fibers, endocardial deformation decreases more compared to epicardial deformation. Since twisting, as described above, is the result of the sum of the (opposite) rotations induced by endo- end epicardial fiber shortening, when endocardial shortening is reduced, this decreases the rotation counteracting the (oppositely) in-

Fetal Diagn Ther 2012;32:5-16 
duced rotation by the epicardial fibers, thus effectively increasing the overall twisting. This, together with increased radial function, is a typical example of a component of deformation which increases as a result of a pathological condition.

Besides these global changes in deformation (especially in strain rate rather than strain), there are regional differences induced by the fact that the local shape and curvature of the muscle is not homogeneous within a ventricle. These differences in local shape result in slight differences in local wall stress [32] which become even more pronounced with increasing pressure in the cavity. In the segments with the highest wall stress (the basal part and predominantly the septum), the hypertrophic response becomes more prominent, resulting in localized thickening of the muscle. A typical manifestation of this is the basal septal bulge, leading to the 'sigmoid' septum, as is present in hypertension [53]. This local change in wall stress not only results in a local alteration of wall thickness, but also induces changes in deformation. Since the wall stress is higher, the resulting contractile force appears smaller and systolic deformation diminishes and postsystolic deformation is induced. Therefore, the presence of reduced systolic deformation and postsystolic shortening/thickening in the basal septal segment is a sensitive indicator of increased pressure loading of the ventricle.

\section{Conclusion}

Contemporary imaging techniques offer the possibility of noninvasive quantification of myocardial deformation. This new clinical tool is attractive to use for the assessment of ventricular function. However, it is of great importance to understand cardiac mechanics - a complex interplay between the tissue structure/shape, force development, and interaction with the environment/ neighbors - to interpret alterations in deformation and extract clinically relevant conclusions. The combination of insight into the measurement techniques and their limitations, together with knowledge of myocardial mechanics and physiology, provides new perspectives to improve the assessment and management of fetal, pediatric, or adult patients.

\section{Acknowledgements}

This study was partially supported by grants from the Centro para el Desarrollo Técnico Industrial (CENIT 20092012, supported by the Ministerio de Ciencia e Innovacion and the Fondo de Inversión Local para el Empleo; Spain), the Ministerio de Ciencia e Innovación (SAF2009-08815), the Cerebra Foundation for the Brain Injured Child (Carmarthen, UK), the Thrasher Research Fund (Salt Lake City, Utah, USA), and the Instituto de Salud Carlos III - Acción Estratégica de Salud (FIS - PI11/01709).

\section{References}

1 Sonnenblick EH, Ross J Jr, Covell JW, Spotnitz HM, Spiro D: The ultrastructure of the heart in systole and diastole: changes in sarcomere length. Circ Res 1967;21:423-431.

$\checkmark 2$ Aurigemma GP, Silver KH, Priest MA, Gaasch WH: Geometric changes allow normal ejection fraction despite depressed myocardial shortening in hypertensive left ventricular hypertrophy. J Am Coll Cardiol 1995;26: 195-202.

3 Parsai C, Bijnens B, Sutherland GR, Baltabaeva A, Claus P, Marciniak M, Paul V, Scheffer M, Donal E, Derumeaux G, Anderson L: Toward understanding response to cardiac resynchronization therapy: left ventricular dyssynchrony is only one of multiple mechanisms. Eur Heart J 2009;30:940-949.

4 Claus P, Weidemann F, Dommke C, Bito V, Heinzel FR, D'hooge J, Sipido KR, Sutherland GR, Bijnens B: Mechanisms of postsystolic thickening in ischemic myocardium: mathematical modelling and comparison with experimental ischemic substrates. Ultrasound Med Biol 2007;33:1963-1970.
5 Sutherland GR, Hatle L, Claus P, D’hooge J, Bijnens BH (eds): Doppler Myocardial Imaging: A Textbook. Hasselt, BSWK, 2006.

6 Bijnens BH, Cikes M, Claus P, Sutherland GR: Velocity and deformation imaging for the assessment of myocardial dysfunction. Eur J Echocardiogr 2009; 10:216-226.

7 Weidemann F, Dommke C, Bijnens B, Claus P, D’hooge J, Mertens P, Verbeken E, Maes A, Van de Werf F, De Scheerder I, Sutherland GR: Defining the transmurality of a chronic myocardial infarction by ultrasonic strain rate imaging: the implications for identifying intramural viability - an experimental study. Circulation 2003;107:883-888.

$\checkmark 8$ Kowalski M, Herbots L, Weidemann F, Breithardt $\mathrm{O}$, Strotmann J, Davidavicius G, D’hooge J, Claus P, Bijnens B, Herregods MC, Sutherland GR: One-dimensional ultrasonic strain and strain rate imaging: a new approach to the quantitation of regional myocardial function in patients with aortic stenosis. Ultrasound Med Biol 2003;29: 1085-1092.
Ishii T, McElhinney DB, Harrild DM, Marcus EN, Sahn DJ, Truong U, Tworetzky W: Circumferential and longitudinal ventricular strain in the normal human fetus. J Am Soc Echocardiogr 2012;25:105-111.

10 Van Mieghem T, Giusca S, DeKoninck P, Gucciardo L, Doné E, Hindryckx A, D’Hooge J, Deprest J: Prospective assessment of fetal cardiac function with speckle tracking in healthy fetuses and recipient fetuses of twinto-twin transfusion syndrome. J Am Soc Echocardiogr 2010;23:301-308.

11 Vyas HV, Eidem BW, Cetta F, Acharya G, Huhta J, Roberson D, Cuneo B: Myocardial tissue Doppler velocities in fetuses with hypoplastic left heart syndrome. Ann Pediatr Cardiol 2011;4:129-134.

12 Comas M, Crispi F, Cruz-Martinez R, Figueras F, Gratacos E: Tissue Doppler echocardiographic markers of cardiac dysfunction in small-for-gestational age fetuses. Am J Obstet Gynecol 2011;205:57.e1-57.e6. 
$\checkmark 13$ Godfrey ME, Messing B, Cohen SM, Valsky DV, Yagel S: Functional assessment of the fetal heart. Ultrasound Obstet Gynecol 2012; 39:131-144.

-14 Crispi F, Bijnens B, Figueras F, Bartrons J, Eixarch E, Le Noble F, Ahmed A, Gratacós E: Fetal growth restriction results in remodeled and less efficient hearts in children. Circulation 2010;121:2427-2436.

-15 Rydman R, Söderberg M, Larsen F, Caidahl $\mathrm{K}$, Alam M: Echocardiographic evaluation of right ventricular function in patients with acute pulmonary embolism: a study using tricuspid annular motion. Echocardiography 2010;27:286-293.

-16 Chrustowicz A, Gackowski A, El-Massri N, Sadowski J, Piwowarska W: Preoperative right ventricular function in patients with organic mitral regurgitation. Echocardiography 2010;27:282-285.

-17 Kjaergaard J, Iversen KK, Akkan D, Møller JE, Køber LV, Torp-Pedersen C, Hassager C: Predictors of right ventricular function as measured by tricuspid annular plane systolic excursion in heart failure. Cardiovasc Ultrasound 2009;7:51

18 Herrmann S, Störk S, Niemann M, Lange V, Strotmann JM, Frantz S, Beer M, Gattenlöhner S, Voelker W, Ertl G, Weidemann F: Lowgradient aortic valve stenosis myocardial fibrosis and its influence on function and outcome. J Am Coll Cardiol 2011;58:402-404.

-19 Sengupta PP, Krishnamoorthy VK, Korinek J, Narula J, Vannan MA, Lester SJ, Tajik JA, Seward JB, Khandheria BK, Belohlavek M: Left ventricular form and function revisited: applied translational science to cardiovascular ultrasound imaging. J Am Soc Echocardiogr 2007;20:539-551.

20 Cárdenes R, Muñoz-Moreno E, Tristan-Vega A, Martin-Fernandez M: Saturn: a software application of tensor utilities for research in neuroimaging. Comput Methods Programs Biomed 2010;97:264-279.

-21 Dokos S, Smaill BH, Young AA, LeGrice IJ: Shear properties of passive ventricular myocardium. Am J Physiol Heart Circ Physiol 2002;283:H2650-H2659.

22 Garot J, Pascal O, Diebold B, Derumeaux G, Gerber BL, Dubois-Rande JL, Lima JA, Guéret P: Alterations in systolic left ventricular twist after acute myocardial infarction. Am J Physiol Heart Circ Physiol 2002; 282:H357-H362.

23 Sedmera D: Function and form in the developing cardiovascular system. Cardiovasc Res 2011;91:252-259.

24 Tobita K, Garrison JB, Liu LJ, Tinney JP, Keller BB: Three-dimensional myofiber architecture of the embryonic left ventricle during normal development and altered mechanical loads. Anat Rec A Discov Mol Cell Evol Biol 2005;283:193-201.
25 Sonne C, Sugeng L, Takeuchi M, Weinert L, Childers R, Watanabe N, Yoshida K, MorAvi V, Lang RM: Real-time 3-dimensional echocardiographic assessment of left ventricular dyssynchrony: pitfalls in patients with dilated cardiomyopathy. JACC Cardiovasc Imaging 2009;2:802-812.

26 Kapetanakis S, Kearney MT, Siva A, Gall N, Cooklin M, Monaghan MJ: Real-time threedimensional echocardiography: a novel technique to quantify global left ventricular mechanical dyssynchrony. Circulation 2005; 112:992-1000.

27 Weidemann F, Jamal F, Sutherland GR, Claus P, Kowalski M, Hatle L, De Scheerder I, Bijnens B, Rademakers FE: Myocardial function defined by strain rate and strain during alterations in inotropic states and heart rate. Am J Physiol Heart Circ Physiol 2002;283:H792-H799.

28 Marciniak A, Claus P, Sutherland GR, Marciniak M, Karu T, Baltabaeva A, Merli E, Bijnens B, Jahangiri M: Changes in systolic left ventricular function in isolated mitral regurgitation: a strain rate imaging study. Eur Heart J 2007;28:2627-2636.

29 Rösner A, Bijnens B, Hansen M, How OJ, Aarsaether E, Müller S, Sutherland GR, Myrmel T: Left ventricular size determines tissue Doppler-derived longitudinal strain and strain rate. Eur J Echocardiogr 2009; 10:271277.

30 Herbots L: Description of Deformation Values in Healthy Volunteers and the Influence of BMI, Age and Gender Assessment of Contractile Function in Endurance Trained Athletes Using Strain Rate and Strain; thesis, University Hospital Gasthuisberg, Leuven, 2006.

31 Kiserud T, Acharya G: The fetal circulation. Prenat Diagn 2004;24:1049-1059.

-32 Choi HF, Rademakers FE, Claus P: Left-ventricular shape determines intramyocardial mechanical heterogeneity. Am J Physiol Heart Circ Physiol 2011;301:H2351-H2361.

33 Lamont RF, Sobel JD, Vaisbuch E, Kusanovic JP, Mazaki-Tovi S, Kim SK, Uldbjerg N, Romero R: Parvovirus B19 infection in human pregnancy. BJOG 2011;118:175-186.

34 Mäkikallio K, Vuolteenaho O, Jouppila P, Räsänen J: Ultrasonographic and biochemical markers of human fetal cardiac dysfunction in placental insufficiency. Circulation 2002;105:2058-2063.

35 Mertens L, Weidemann F, Sutherland GR: Left ventricular function before and after repair of an anomalous left coronary artery arising from the pulmonary trunk. Cardiol Young 2001;11:79-83.

36 Bijnens B, Claus P, Weidemann F, Strotmann J, Sutherland GR: Investigating cardiac function using motion and deformation analysis in the setting of coronary artery disease. Circulation 2007;116:2453-2464.
37 Claus P, Weidemann F, Dommke C, Bito V, Heinzel FR, D'hooge J, Sipido KR, Sutherland GR, Bijnens B: Mechanisms of postsystolic thickening in ischemic myocardium: mathematical modelling and comparison with experimental ischemic substrates. Ultrasound Med Biol 2007;33:1963-1970.

38 Bragadeesh T, Jayaweera AR, Pascotto M, Micari A, Le DE, Kramer CM, Epstein FH, Kaul S: Post-ischaemic myocardial dysfunction (stunning) results from myofibrillar oedema. Heart 2008;94:166-171.

39 Turschner O, D'hooge J, Dommke C, Claus P, Verbeken E, De Scheerder I, Bijnens B, Sutherland GR: The sequential changes in myocardial thickness and thickening which occur during acute transmural infarction, infarct reperfusion and the resultant expression of reperfusion injury. Eur Heart J 2004; 25:794-803.

40 Merli E, Sutherland GR, Bijnens B, Fischer A Chaparro M, Karu T, Sutcliffe S, Marciniak A, Baltabaeva A, Bunce N, Brecker S: Usefulness of changes in left ventricular wall thickness to predict full or partial pressure reperfusion in ST-elevation acute myocardial infarction. Am J Cardiol 2008;102:249-256.

41 Pedra SR, Smallhorn JF, Ryan G, Chitayat D, Taylor GP, Khan R, Abdolell M, Hornberger LK: Fetal cardiomyopathies: pathogenic mechanisms, hemodynamic findings, and clinical outcome. Circulation 2002;106:585591.

42 Cikes M, Sutherland GR, Anderson LJ, Bijnens BH: The role of echocardiographic deformation imaging in hypertrophic myopathies. Nat Rev Cardiol 2010;7:384-396.

43 Weidemann F, Breunig F, Beer M, Sandstede J, Störk S, Voelker W, Ertl G, Knoll A, Wanner C, Strotmann JM: The variation of morphological and functional cardiac manifestation in Fabry disease: potential implications for the time course of the disease. Eur Heart J 2005;26:1221-1227.

44 Brace V, Grant SR, Brackley KJ, Kilby MD, Whittle MJ: Prenatal diagnosis and outcome in sacrococcygeal teratomas: a review of cases between 1992 and 1998. Prenat Diagn 2000;20:51-55

-45 Berg C, Kamil D, Geipel A, Kohl T, Knöpfle G, Hansmann M, Gembruch U: Absence of ductus venosus: importance of umbilical venous drainage site. Ultrasound Obstet Gynecol 2006;28:275-281.

46 Karatza AA, Wolfenden JL, Taylor MJ, Wee L, Fisk NM, Gardiner HM: Influence of twin-twin transfusion syndrome on fetal cardiovascular structure and function: prospective case-control study of 136 monochorionic twin pregnancies. Heart 2002;88:271277. 
-47 Barrea C, Alkazaleh F, Ryan G, McCrindle BW, Roberts A, Bigras JL, Barrett J, Seaward GP, Smallhorn JF, Hornberger LK: Prenatal cardiovascular manifestations in the twinto-twin transfusion syndrome recipients and the impact of therapeutic amnioreduction. Am J Obstet Gynecol 2005;192:892902.

48 Mäkikallio K, McElhinney DB, Levine JC, Marx GR, Colan SD, Marshall AC, Lock JE, Marcus EN, Tworetzky W: Fetal aortic valve stenosis and the evolution of hypoplastic left heart syndrome: patient selection for fetal intervention. Circulation 2006;113:1401-1405.
49 Roman KS, Fouron JC, Nii M, Smallhorn JF, Chaturvedi R, Jaeggi ET: Determinants of outcome in fetal pulmonary valve stenosis or atresia with intact ventricular septum. Am J Cardiol 2007;99:699-703.

50 Gardiner HM, Belmar C, Tulzer G, Barlow A, Pasquini L, Carvalho JS, Daubeney PE, Rigby ML, Gordon F, Kulinskaya E, Franklin RC: Morphologic and functional predictors of eventual circulation in the fetus with pulmonary atresia or critical pulmonary stenosis with intact septum. J Am Coll Cardiol 2008;51:1299-1308.

51 Rychik J, McCann M, Tian Z, Bebbington M, Johnson MP: Fetal cardiovascular effects of lower urinary tract obstruction with giant bladder. Ultrasound Obstet Gynecol 2010; 36:682-686.
52 Cikes M, Kalinic H, Hermann S, Lange V, Loncaric S, Milicic D, Beer M, Cikes I, Weidemann F, Bijnens B: Does the aortic velocity profile in aortic stenosis patients reflect more than stenosis severity? The impact of myocardial fibrosis on aortic flow symmetry. Eur Heart J 2009;30(suppl 1):605.

53 Baltabaeva A, Marciniak M, Bijnens B, Moggridge J, He FJ, Antonios TF, MacGregor GA, Sutherland GR: Regional left ventricular deformation and geometry analysis provides insights in myocardial remodelling in mild to moderate hypertension. Eur J Echocardiogr 2008;9:501-508. 